\title{
AUTOCICATRIZAÇÃO DO CONCRETO E OS EFEITOS DA ADIÇÃO DE ADITIVOS CRISTALIZANTES EM SUA COMPOSIÇÃO
}

\author{
L. A. H. WIENER \\ Engenheiro \\ PUCRS \\ Rio Grande do Sul; Brasil \\ e-mail: wienerleonardo@gmail.com
}

\author{
A. B. ROHDEN \\ Professor \\ PUCRS e FURB \\ Rio Grande do Sul; Brasil \\ e-mail: abrcivil@gmail.com
}

\section{RESUMO}

A impermeabilização é uma etapa muito importante na construção civil, quando não tratada com devida importância pode ocasionar manifestações patológicas graves e custos altíssimos em reparos. Este artigo tem como objetivo analisar a eficiência de um aditivo cristalizante incorporado à elementos de concreto armado quando submetido a flexão com abertura de fissura igual a $0,4 \mathrm{~mm}$. Para isso foi proposto um ensaio adaptando-se normativas similares no qual se aplicou uma coluna de água de 1 metro de coluna d'água em uma laje previamente fissurada. Os concretos estudados ficaram em carga antes e após o processo de fissuração. Os resultados motram que o aditivo não alterou as características mecânicas do concreto. O ensaio proposto simula condições de aplicação do concreto sendo uma alternativa para avaliação do desempenho dos aditivos. No trabalho também foram algumas falhas que podem impactar nos resultados observados.

\section{Palavras-chave: auto cicatrização, impermeabilização, permeabilidade.}

\begin{abstract}
Waterproofing is a very important step in construction, when not treated with due importance can cause serious pathological manifestations and high costs in repairs. This article aims to analyze the efficiency of a crystallizing additive incorporated to reinforced concrete elements when subjected to bending with a crack opening of $0.4 \mathrm{~mm}$. For this purpose, it was proposed an adaptation of similar norms in which a water column of 1 meter of water column was applied to a previously cracked slab. The studied concretes were in charge before and after the cracking process. The results show that the additive did not change the mechanical characteristics of the concrete. The proposed test simulates concrete application conditions and is an alternative for evaluating the performance of additives. At work were also some failures that may impact the results observed.
\end{abstract}

Keywords: self healing, waterproofing, permeability.

\section{INTRODUÇÃO}

Considerada ainda como um desafio para a construção civil, a umidade é uma preocupação constante, resultante das más práticas executivas e ou falhas de projeto de impermeabilização. Entre os principais problemas em obras, a falta ou a má execução de impermeabilização é sempre um dos mais citados dentre os problemas. Pois pela falta de mão de obra especializada, fiscalização e más práticas, a impermeabilização não está sendo tratada com a necessária importância (RIGHI, 2009).

A impermeabilização é considerada um serviço especializado da construção civil. O IBI (Instituto Brasileiro de Impermeabilização) é a constatação da importância deste segmento na construção civil, o que mostra credibilidade entre os fabricantes e o constante desenvolvimento de métodos executivos e normatizações realizadas nos produtos existentes no mercado. A desinformação a respeito das técnicas e materiais de impermeabilização são em grande maioria os principais responsáveis pelo insucesso nos processos. 
Fundamental para durabilidade das edificações, a impermeabilização configura risco direto ao surgimento de manifestações patológicas ao longo da vida útil da edificação. $\mathrm{O}$ aparecimento de umidade, eflorescências, manchas, bolores, oxidação da armadura, desplacamento de revestimento cerâmicos e outros, são causas diretamente relacionadas à falta de impermeabilização. Diante destas manifestações patológicas a necessidade de um projeto de impermeabilização adequado se faz extremamente necessário (RIGHI, 2009).

A Associação Brasileira de Normas Técnicas (ABNT) desenvolveu a NBR 9574 (ABNT, 2008), que estabelece exigências na execução de impermeabilização, e NBR 9575 (ABNT, 2010), que estabelece as exigências e recomendações relativas ao projeto de impermeabilização. Existem no Brasil diversos produtos impermeabilizantes disponíveis no mercado, de qualidade e desempenho variável, de diversas origens e métodos de aplicação, normatizados ou não, é de responsabilidade do projetista orientar a técnica mais adequada para o sistema de impermeabilização .Deve-se conhecer as necessidades exigidas da edificação, conhecer os parâmetros físicos e químicos de todo o sistema de impermeabilização a ser adotado e assim e orientar a correta técnica (RIGHI, 2009).

O custo de implementação de um sistema de impermeabilização em uma edificação representa valores baixos em relação aos custos envolvidos em ações paliativas e ou reconstrutivas pela falta da mesma. O desenvolvimento do projeto de impermeabilização juntamente com os projetos executivos da obra é o cenário mais econômico (SIQUEIRA, 2018). A escolha do sistema de impermeabilização depende das circunstâncias onde será utilizado, o fator econômico é o maior limitador na escolha destes sistemas, porém não se deve considerar somente o preço da camada impermeável, mas também os custos das demais camadas que englobam o sistema. Aditivos cristalizantes incorporados ao concreto vêm sendo comumente empregados em edificações afim de solucionar problemas de infiltração em reservatórios, piscinas, lajes de cobertura, subsolos e outros (TAKAGI, 1996).

O objetivo principal deste trabalho é analisar a influência de aditivos cristalizantes incorporados ao concreto, visando caracterizar possível auto cicatrização de fissuras no concreto, aplicado em elemento estrutural fletido.

\section{REVISÃO BIBILIOGRÁFICA}

O concreto é um material de construção constituído de uma mistura de um aglomerante com um ou mais materiais inertes e água. Quando recém-misturado, deve oferecer condições de plasticidade que facilitem as operações de manuseio indispensáveis ao lançamento nas formas, adquirindo, com o tempo, pelas reações que então se processarem entre aglomerante e água, coesão e resistência a compressão (PETRUCCI, 1996).

O concreto é um material que, por sua própria constituição é necessariamente poroso, pois não é possível preencher a totalidade dos vazios do agregado com a pasta de cimento (PETRUCCI, 1996). A porosidade é uma característica de fundamental importância na qualidade do concreto, visto ser responsável diretamente, tanto por sua resistência mecânica como pela durabilidade (RECENA, 2016).

Quanto maior a quantidade de poros interligados na estrutura interna de um concreto maior será sua permeabilidade, portanto reduzindo a sua durabilidade, pois estará suscetível a agentes agressores externos. Enquanto a porosidade se refere à totalidade dos vazios e a absorção é função dos poros que têm comunicação com o exterior, a permeabilidade tem relação com a continuidade destes canais. A permeabilidade é uma propriedade vital para previsão da durabilidade de uma estrutura de concreto. A facilidade de penetração da água, transportando agentes agressivos ao concreto, acontece preferencialmente na região de interface pasta-agregado (FURNAS, 2002).

As razões são varias para o aparecimento de vazios entre pasta-agregado: a) é sempre necessário utilizar uma quantidade de água superior à que se precisa para hidratar o aglomerante, e essa água, denominada água de amassamento, ao evaporar, deixa vazios; b) inevitavelmente, durante a mistura do concreto, incorpora-se ar à massa, causando assim aparecimento de vazios. A interconexão desses vazios de água ou ar torna o concreto permeável à água (PETRUCCI, 1996).

Fissuras são sempre indesejáveis, no mínimo por emprestarem à peça mau aspecto e transmitirem a sensação de que há um defeito. E há (RECENA, 2016). Um dos grandes problemas encontrados nas construções, é a fissuração excessiva em estruturas de concreto, podendo ser originado por erro de projeto, execução da estrutura, falha dos materiais empregados ou por mau uso da estrutura (CUNHA, 2011). 
Diversas são as circunstâncias que podem acarretar a formação de fissuras em peças de concreto armado. Pode-se diferenciar as fissuras produzidas por solicitações devidas ao carregamento, que são causas por ações diretas de tração, flexão ou cisalhamento, e as fissuras não produzidas por carregamentos, que são causadas por deformações impostas, como temperatura, retração e recalques (CUNHA, 2011).

A auto cicatrização pode ocorrer de forma autógena ou induzida por adições de minerais na sua dosagem. A auto cicatrização autógena ocorre por colmatação natural do concreto, com o preenchimento e selamento das fissuras em função de reações químicas inerentes ao concreto, a hidratação de cimento residual e a carbonatação ou o bloqueio mecânico da face interna da fissura. Os mecanismos com uma maior capacidade de cicatrização dependem de componentes especiais como catalisadores cristalinos e outros (TAKAGI, 1996).

Nos concretos em geral, a auto cicatrização natural ocorre de forma limitada, corrigindo, por colmatação, fissuras com aberturas de até $0,2 \mathrm{~mm}$ e desde que haja condições adequadas para a formação dos produtos de preenchimento (Figura $1)$.
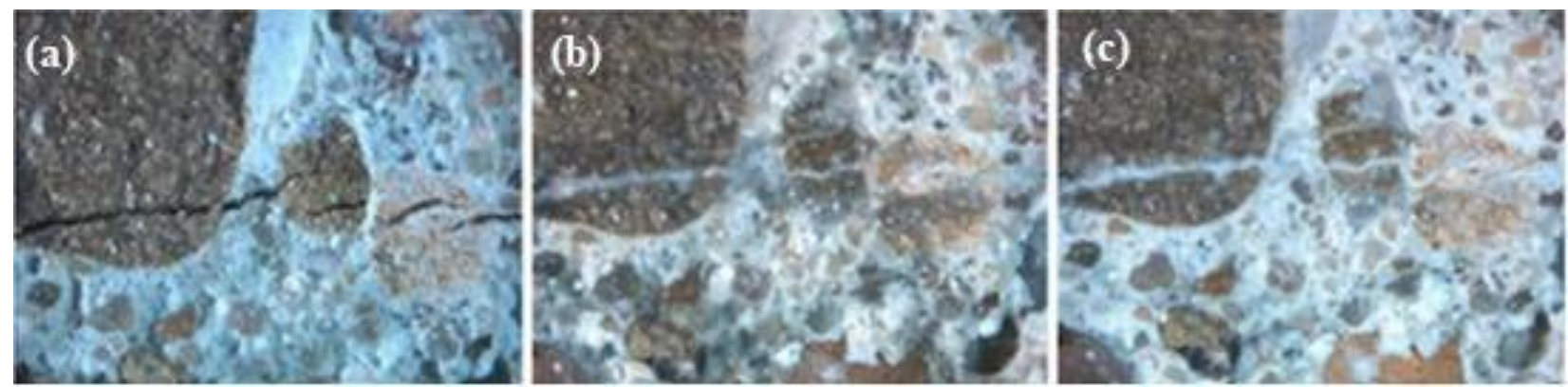

Figura 1: Ilustração do efeito da autocicatrização (a) fissura inicial, (b) após 15 dias em contato com a umidade e (c) após 30 dias em contato com a umidade. Fonte: TAKAGI, 1996.

A impermeabilização é considerada uma barreira física, cuja finalidade é a de evitar a água que penetra por capilaridade, a água da chuva que infiltra, a percolação de água indesejável, ou de dirigi-la para os pontos de escoamento fora da área que se deseja proteger (CRUZ, 2003). Os aditivos cristalizantes são substâncias que embora se espalhem muito bem na água, são nela insolúveis, depositando-se nos canais e poros capilares formados nas argamassas e concretos quando a água evapora (VERDOÇA, 1987).

Para o tratamento do concreto, a impermeabilização por adição de cristalizantes define-se como processo físico-químico, com o objetivo de preencher os poros e capilaridades, impedindo a penetração de água, suportando pressões hidrostáticas positivas e negativas (MAKI; KURAMOTO; NAKAMURA, 1991). Estes compostos químicos ativos reagem com a umidade do concreto fresco e com os produtos da hidratação do cimento, formando uma estrutura cristalina insolúvel nos poros e capilaridades do concreto. Desta maneira o concreto torna-se permanentemente selado contra a penetração de água e outros líquidos (PENETRON, 2018).

$\mathrm{O}$ aditivo mineral cristalizante em forma de pó adicionado à mistura fresca do concreto reage com os compostos da pasta de cimento e proporciona diversas propriedades para a impermeabilização, preenchendo os poros do concreto e fissuras de até $0,4 \mathrm{~mm}$. Isso impede a penetração da água, mas permite a passagem do vapor d'água, evitando a pressão de vapor dentro da estrutura, assim prolongando sua vida útil (PENETRON, 2018).

Esta tecnologia baseada em sais de silicatos e na química dos argilominerais como agente catalisador, que denomina-se neste trabalho como catalisador X, tirar vantagem das características inerentes do concreto de porosidade e reatividade química por natureza. Por meio do mecanismo de difusão, os agentes catalisadores usam a água como meio migrante para entrar e permear através das capilaridades do concreto, reagindo com os produtos químicos inertes presentes nos poros do concreto (hidróxido de cálcio, sais minerais, óxidos minerais e partículas de cimento não hidratadas e sub hidratadas), sem provocar outras reações descontroladas, preservando os componentes da própria estrutura (Figura 2). Por ser catalítico, o processo pode se reativar sempre que houver a presença de água, mesmo depois da aplicação original (INSTITUTO BRASILEIRO DO CONCRETO, 2016). 

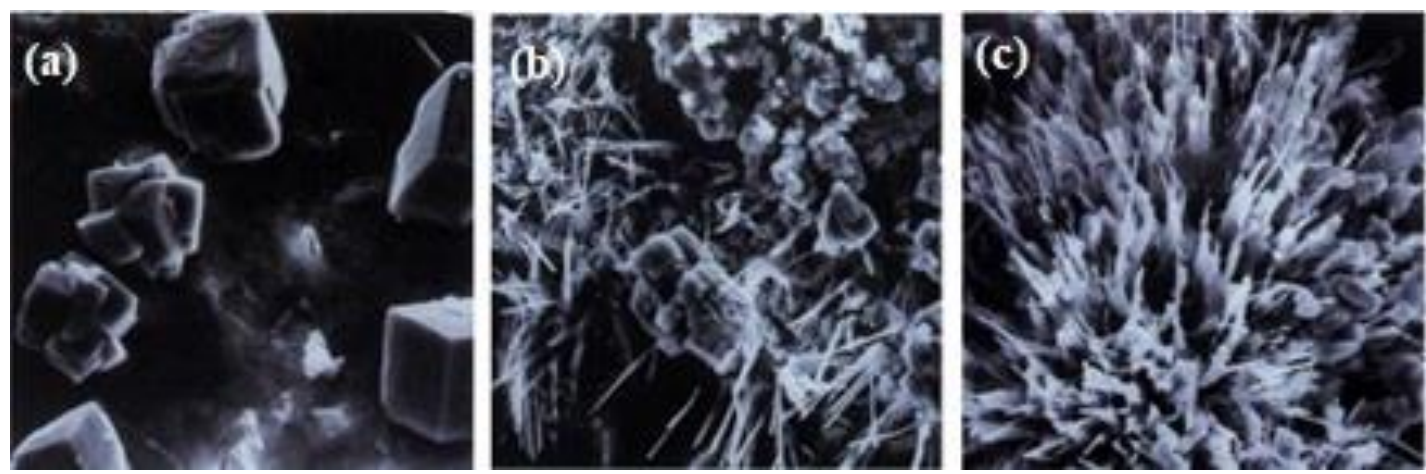

Figura 2: Ilustração do efeito da auto cicatrização (a) fissura inicial, (b) após 15 dias em contato com a umidade e (c) após 30 dias em contato com a umidade. Fonte: Instituto Brasileiro do Concreto, 2016.

\section{MATERIAIS E MÉTODOS}

\subsection{Materiais}

O traço de concreto utilizado nesta pesquisa foi desenvolvido por empresa especializada em pisos estruturais para uma aplicação em obra na cidade de Porto Alegre, para definição do traço e do aditivo utilizado foram realizados estudos preliminares que não são apresentados nesta pesquisa. O traço utilizado é apresentado na Tabela 1 apresenta resistecia característica de $35 \mathrm{MPa}$ e abatimento de $200 \pm 30 \mathrm{~mm}$.

\begin{tabular}{l|c}
\multicolumn{2}{l}{ Tabela 1: Traços utilizados no trabalho } \\
\hline Material & $\mathrm{kg} / \mathrm{m}^{3}$ \\
\hline Cimento CP V ARI - RS & 357 \\
\hline Pozolana & 63 \\
\hline Areia fina & 752 \\
\hline Brita zero & 133 \\
\hline Brita 1 & 752 \\
\hline Aditivo plastificante & 0,84 \\
\hline Aditivo superplastificante & 0,63 \\
\hline Água & 191 \\
\hline Aditivo cristalizante & 2,86 \\
\hline \multicolumn{2}{l}{ Fonte: Fornecedor de concreto, 2019.}
\end{tabular}

\subsection{Métodos}

Na figura 3 são apresentadas as principais etapas do trabalho. Todos os ensaios foram realizados com concretos de um mesmo caminhão betoneira. Inicialmente coletou-se uma amostra de concreto para moldagem de corpos de prova do concreto antes mistura do aditivo cristalizante. Após a incorporação do aditivo novamente foram moldados concretos com o aditivo já incorporado.

Foram moldados 16 corpos de prova conforme NBR 5738 (ABNT, 2015), foram utilizados moldes plásticos cilíndricos de $10 \mathrm{~cm}$ de diâmetro e $20 \mathrm{~cm}$ de altura. Para a moldagem de oito corpos de prova com concreto sem aditivo cristalizante e oito corpos de prova com concreto com aditivo cristalizante.

O abatimento foi verificado conforme norma NBR NM 67 (ABNT, 1998), obtendo-se resultados iguais para ambos os concretos, pois a adição do aditivo cristalizante foi realizada após verificação de abatimento inicial de $50 \mathrm{~mm}$ abatimento (Figura 4) corrigido de $205 \mathrm{~mm}$ (Figura 5). Para chegar ao abatimento final de $205 \mathrm{~mm}$ foi adicionada água e aditivo superplastificante conforme indicado no traço.

A resistência à compressão foi verificada conforme NBR 5738 (ABNT, 2015) e NBR 5739 (ABNT, 2007). Foram rompidos dois corpos de prova com concreto com aditivo cristalizante e dois corpos de prova com concreto sem aditivo cristalizante, sendo identificados como CP1 e CP2 (sem aditivo cristalizante) e CPA1 e CPA2 (com aditivo cristalizante). 
As amostras de cada grupo foram rompidas na prensa hidráulica da marca EMIC (Figura 8), na idade de 7 e 28 dias para verificação da resistência à compressão axial.

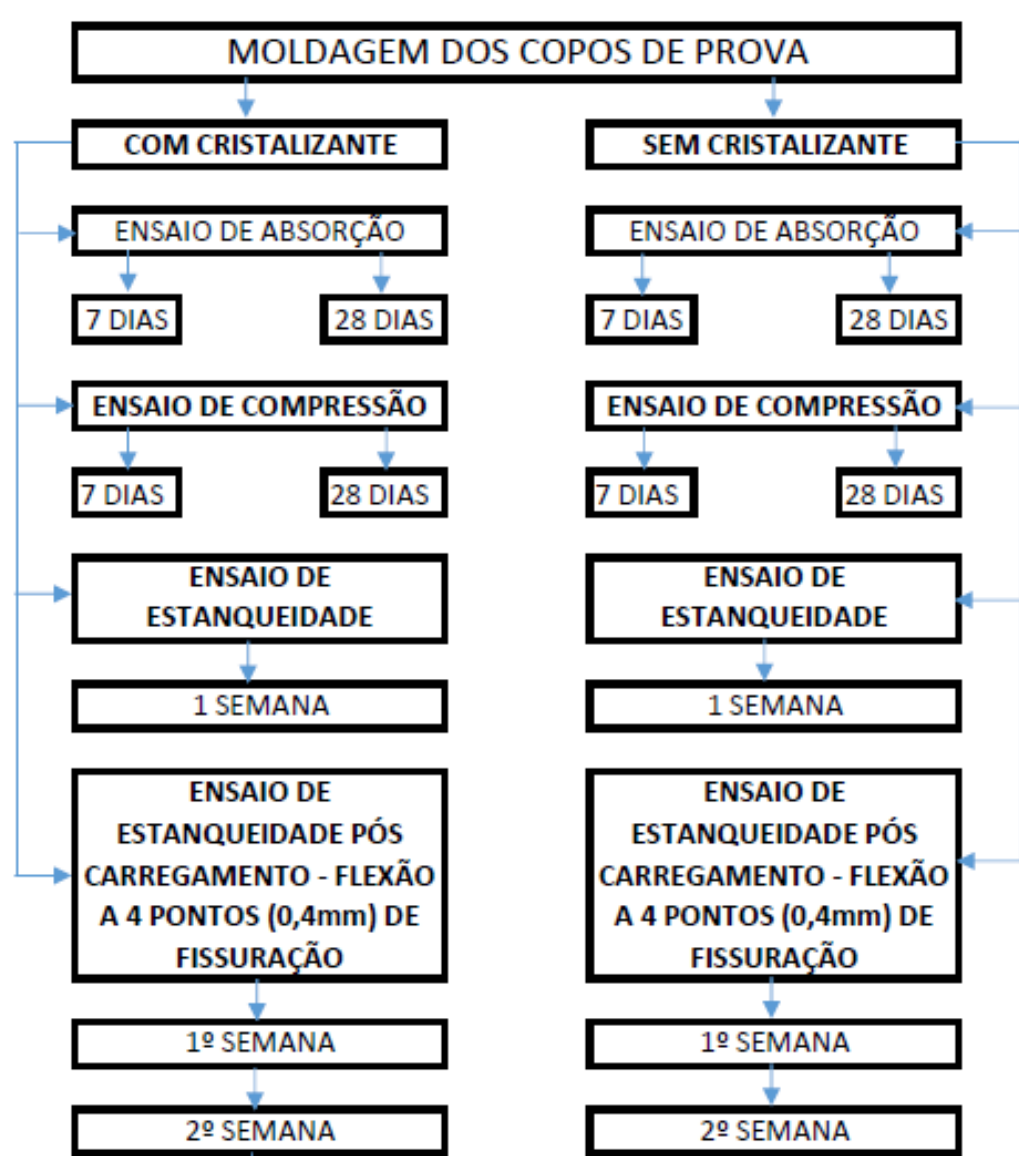

Figura 3: Principais etapas do trabalho.

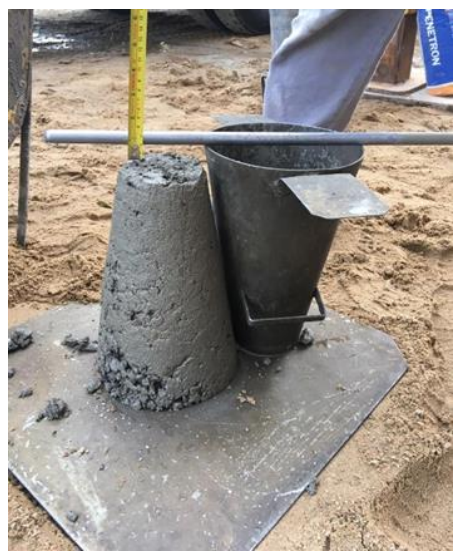

Figura 4: Slump Inical.

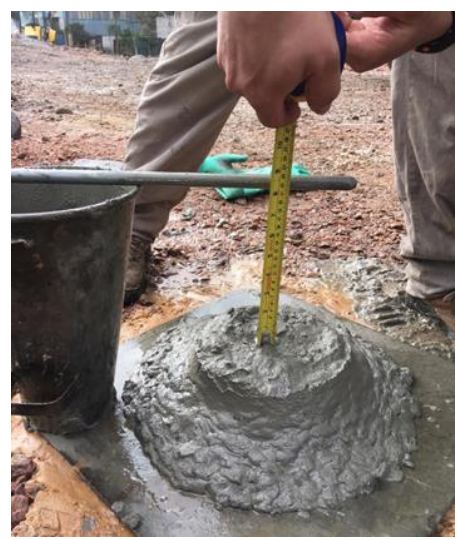

Figura 5: Slump Corrigido.

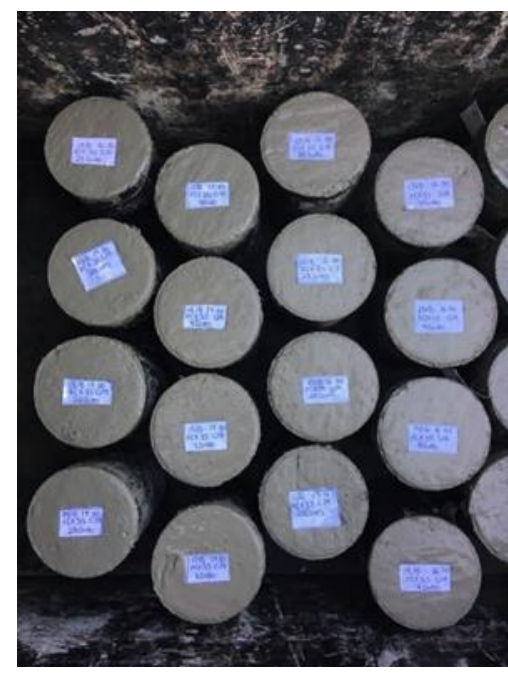

Figura 6: Corpos de prova identificados após a moldagem.

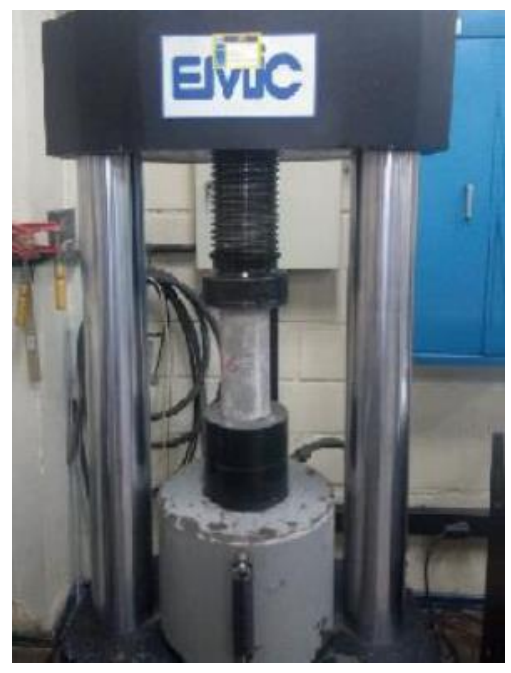

Figura 7: Ruptura dos corpos de prova.

A determinação de absorção de água por imersão foi verificada conforme NBR 9779 (ABNT, 2012). Para este ensaio foram utilizados dois corpos de prova cilíndricos com o traço de referência com aditivo cristalizante e o traço de referência sem aditivo cristalizante, para 7 e 28 dias, de acordo com a NBR 7215 (ABNT 2019), totalizando oito corpos de prova. Após $24 \mathrm{~h}$ os corpos de prova foram desmoldados e postos em cura por 7 e 28 dias, em seguida colocados na estufa por $72 \mathrm{~h}$, após sua completa secagem os corpos de provam foram pesados afim de se obter sua massa seca, logo depois foram 
imersos em um recipiente preenchido com água. Após $72 \mathrm{~h}$ de imersão na água os corpos de prova foram pesados, dessa maneira foram determinadas as massas saturadas das amostras.

Para analisar a influência do aditivo cristalizante incorporado ao concreto e o efeito da auto cicatrização após surgimento de fissuras, foi utilizado como referência o método de verificação de permeabilidade em telhas de concreto NBR 13858 2 (ABNT, 2009), pela verificação da permeabilidade através de pressão de coluna de água, evidenciando vazamento ou não, formação de gotas aderentes e aparecimento de manchas de umidade. Com base na metodologia de ensaios foram moldadas dos corpos de prova com dimensões de $30 \mathrm{~cm}$ x $100 \mathrm{~cm}$ x $7 \mathrm{~cm}$, com armadura de tela eletrosoldada tipo Q138 com cobrimento de 1,5 cm na face inferior (Figura 8), concretadas com concreto usinado com o traço de referência de mesmo lote, sendo uma laje concretada sem adição de cristalizante e uma laje concretada com adição de cristalizante (Figura 9). Após concretadas, as lajes permaneceram em repouso em ambiente de temperatura entre $15^{\circ} \mathrm{C}$ e $25^{\circ} \mathrm{C}$ por 14 dias (Figura 10), após esse período foram levadas ao laboratório, onde permaneceram até a idade de 28 dias para então serem realizados os ensaios.

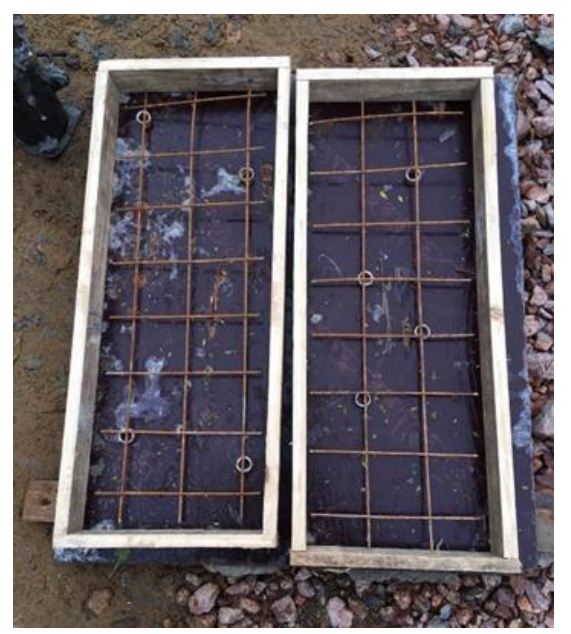

Figura 8: Disposição da armadura.

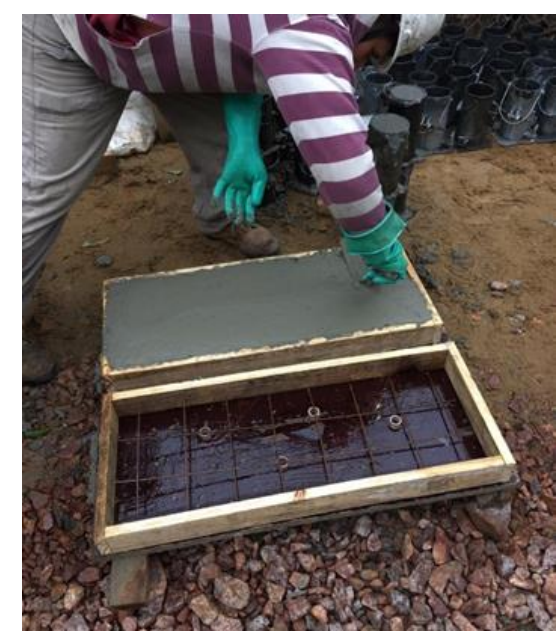

Figura 9: Acabamento superficial.

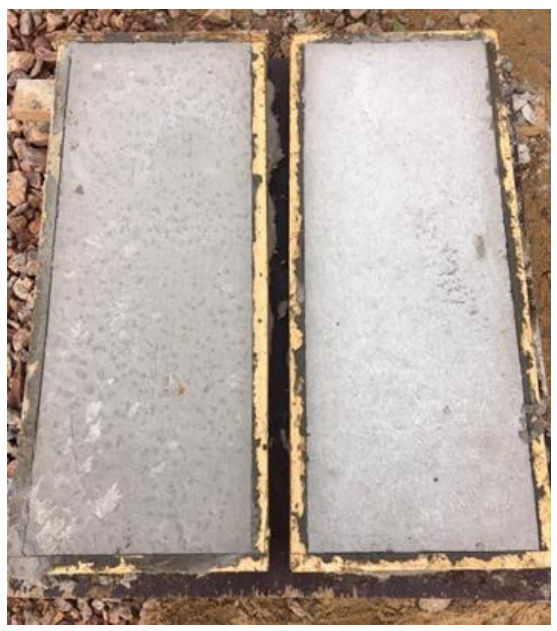

Figura 10: Lajes Concretadas.

Para a avaliação da permeabilidade não fissurada adaptou-se o ensaio prescreto na NBR 13858-2, (ABNT 2009), utilizando-se tubo cilíndrico de $120 \mathrm{~mm}$ de diâmetro e altura de coluna d'água de $1.000 \mathrm{~mm}$, para ter-se condições compativeis com as de aplicação do concreto em obra (Figura 11). Os tubos foram fixados com auxílio de massa de vedação.

Após o preenchimento dos tubos com água os mesmos foram monitorados durante uma semana, através da observação do nível de água no interior do tubo. O dispositivo foi desmontado e aplicou-se cargas de flexão (Figura 12) às placas ensaiadas para fissuração das lajes de concreto armado, afim de se obter uma fissura igual a 0,4 mm (Figura 13). Tal limite de fissuração deve-se ao fato de que o aditivo cristalizante se propõe a realizar a colmatação das fissuras até este limite de abertura de fissura. O ensaio foi realizado por flexão a três pontos com prensa hidráulica EMIC.

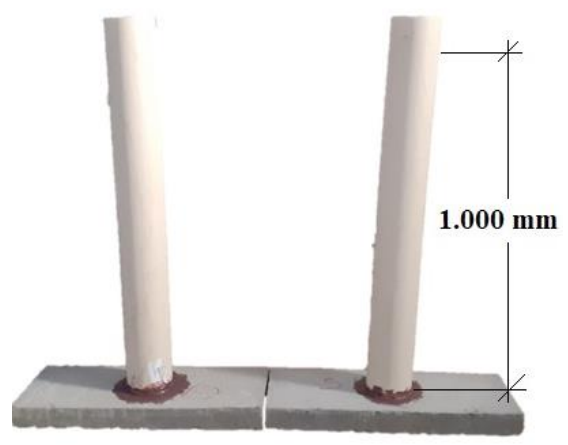

Figura 11 - Dispositivo utilizado no ensaio para aplicação da coluna de água.

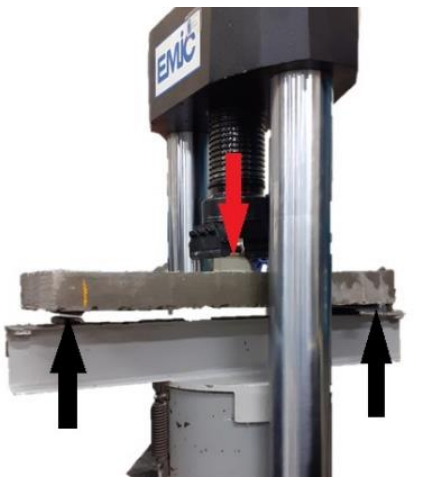

Figura 12 - Aplicação de de carga para fissuração do corpo de prova.

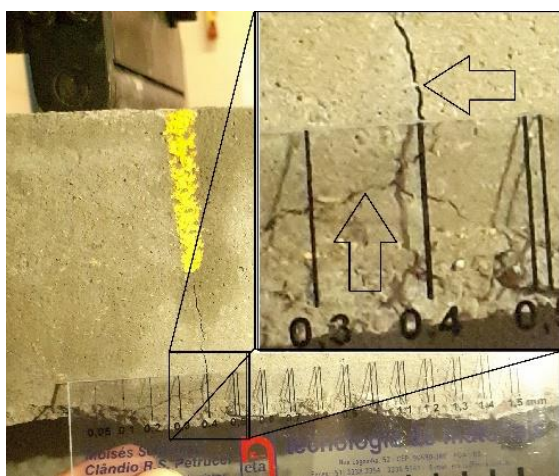

Figura 13 - Fissura após aplicação de carga $(0,4 \mathrm{~mm})$. 
Após aplicação de carga de flexão e abertura da fissura dispositivo foi novamente montado com os tubos cilíndricos e novamente carregados com altura de coluna d'água de $1.000 \mathrm{~mm}$ sendo monitorado por duas semanas.

\section{RESULTADOS}

Os resultados obtidos pelo ensaio de compressão são apresentados na Figura 14 onde se pode observar uma diferença pequena entre os valores de resistência do concreto com e sem aditivo tanto aos 7 quanto aos 28 dias de idade. Os resultados obtidos pelo ensaio de absorção de água por imersão são apresentados na Figura 15 onde se pode observar pequena variação da absorção do concreto com e sem adivito nas idades de 7 e 28 dias de idade. Sendo ambos enquadrados como concretos convencionais, segundo crítérios da NBR 9779 (ABNT, 2012).

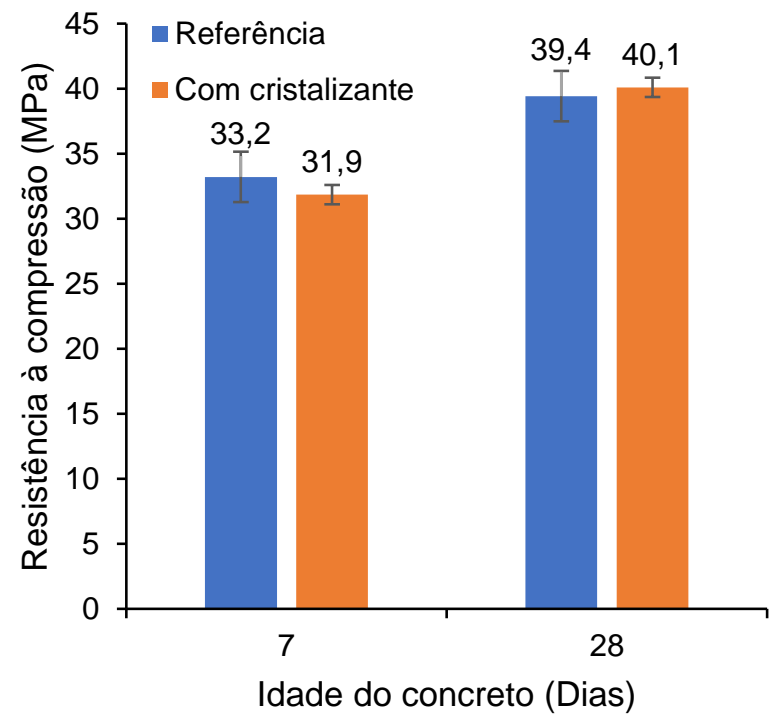

Figura 14: Resultado do ensaio de resistência à compressão.

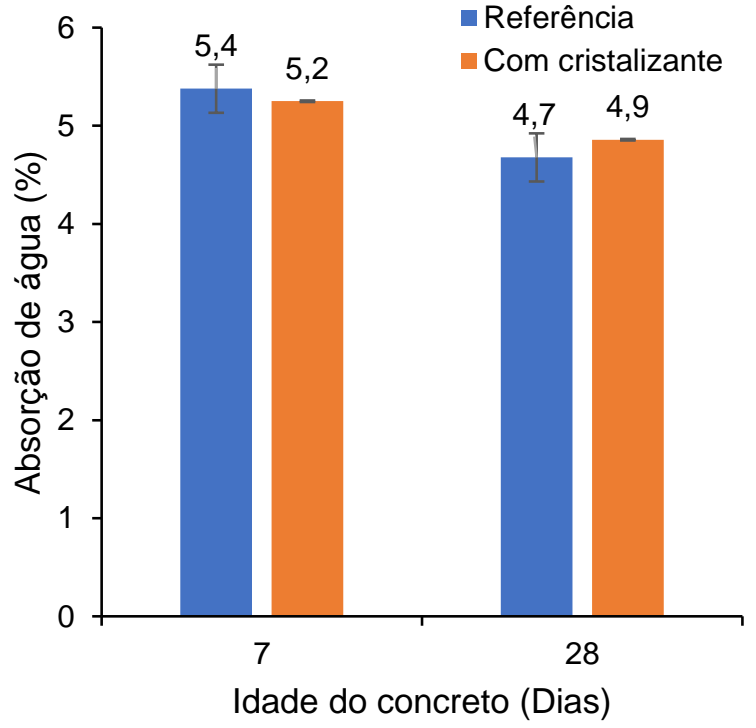

Figura 15: Resultado do ensaio de absorção por imersão.

No ensaio de permeabilidade do concreto verificou-se que imediatamente após o preeenchimento dos tubos com água a laje com aditivo cristalizante apresentou gotejamento na sua parte inferior (Figura 16), evidenciando possível nicho de concretagem no interior do elemento pois a laje sem aditivo cristalizante permaneceu seca na sua face inferior (Figura 17).

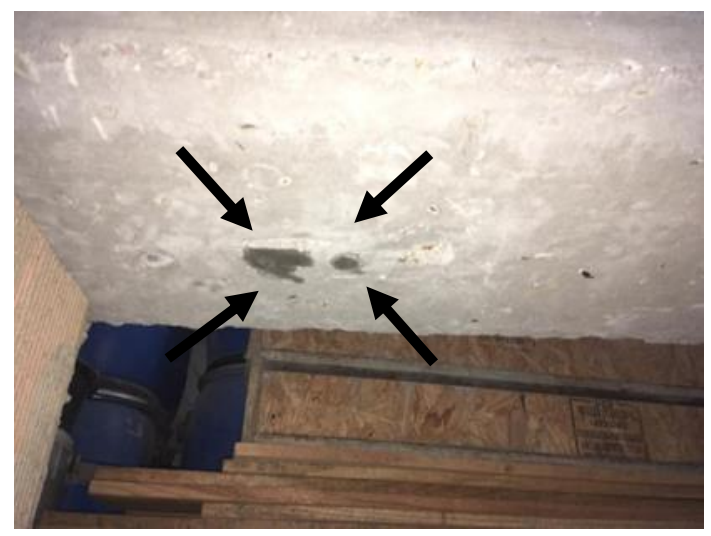

Figura 16: Dia 1 face inferior da placa com aditivo.

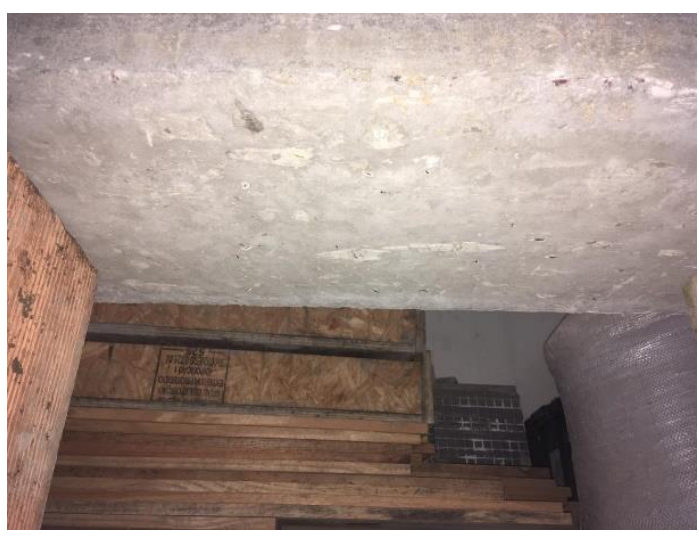

Figura 17: Dia 1 face inferior da placa referência.

O dispositivo foi ensaiando durante 1 semana, após este período foi constatado que o gotejamento existente na placa com aditivo cristalizante já não mais existia (Figura 18), mas se mantendo uma mancha de umidade na sua face inferior. A placa sem aditivo cristalizante se manteve livre de qualquer umidade na sua face inferior (Figura 19). 


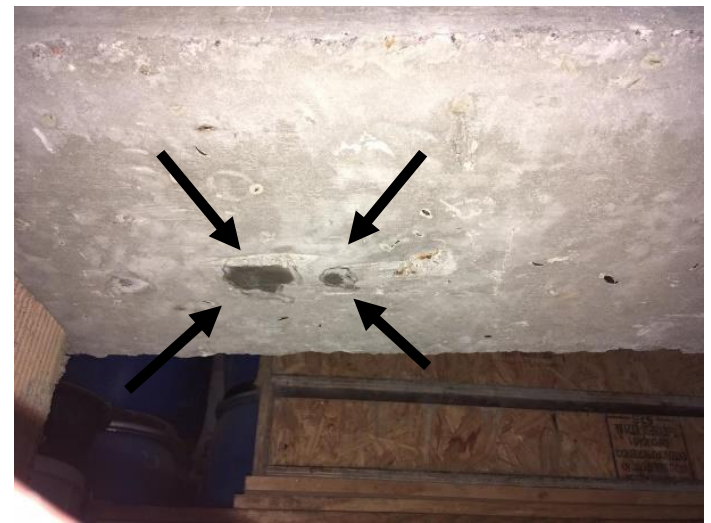

Figura 18: Dia 7 face inferior da placa com aditivo

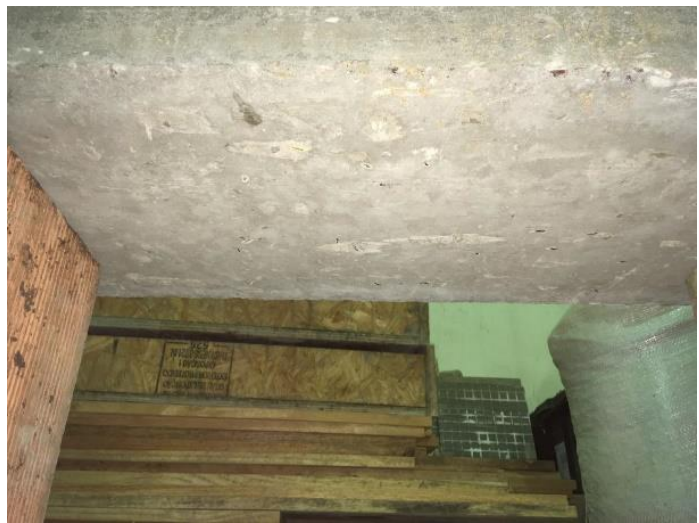

Figura 19: Dia 7 face inferior da placa referência.

Após abertura das fissuras nas lajes de concreto, novamente o dispositivo foi montado com as mesmas características anteriores. Imediatamente após o carregamento hidráulico o aparecimento gotejamento na placa com aditivo cristalizante foi constatado (Figura 20), a placa sem a presença do aditivo cristalizante não apresentou nenhuma umidade imediatamente ao carregamento hidráulico (Figura 21).

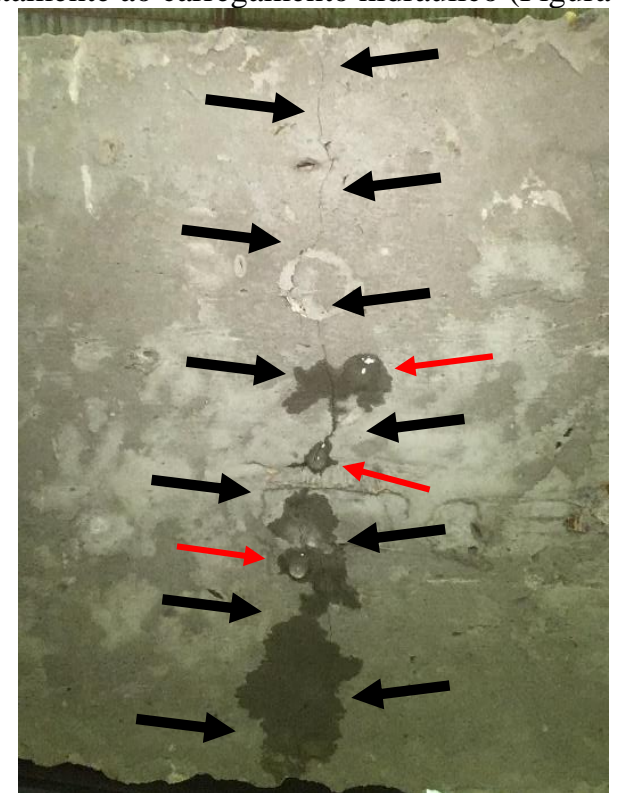

Figura 20: Dia 1 face inferior da placa com aditivo após fissuração.

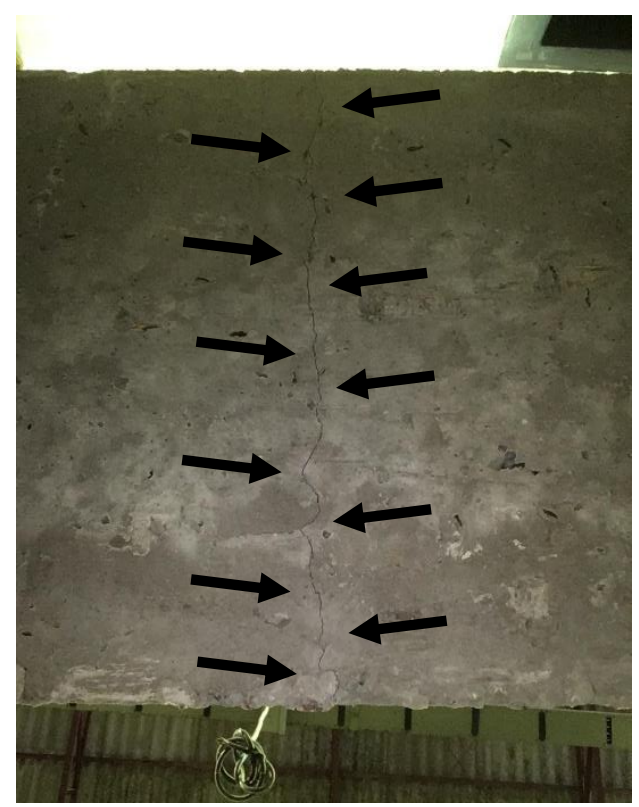

Figura 21: Dia 1 face inferior da placa referência após firruração.

O dispositivo foi ensaiando durante 1 semana, após este período foi constatado que o gotejamento existente na placa com aditivo cristalizante foi diminuindo sua intensidade e apresentando sinais de lixiviação, causado pela dissolução e transporte de hidróxido de cálcio, estes produtos de hidratação apresentam como característica principal o aparecimento de manchas brancas, neste caso a lixiviação acaba realizando a colmatação desta fissura, o que torna-se benéfico. mas se mantendo uma mancha de umidade maior que inferior da laje (Figura 22). A placa sem aditivo cristalizante apresentou umidade no inferior (Figura 23).

O dispositivo permaneceu em carga hidráulica por mais uma semana, totalizando duas semanas de ensaio com as lajes fissuradas. A laje com aditivo cristalizante apresentou sinais claros de formações de cristais de hidróxido de cálcio, manchas brancas por toda região úmida da placa (Figura 24, 25 e 26) e até mesmo no chão (Figura 29), local onde o gotejamento ocorreu. A laje sem aditivo cristalizante permaneceu úmida, porém sem sinais de lixiviação (Figura 27).

Afim de tentar evidenciar a formações de manchas brancas realizadas pela lixiviação no interior da placa de concreto e identificar o possível nicho de concretagem (Figura 32) que ocasionou a precosse percolação de água (Figura 31), roupeuse a placa de concreto na prensa hidráulica (Figura 30). Tal nicho de concretagem pode ser notada em função do espaçador utilizado. 


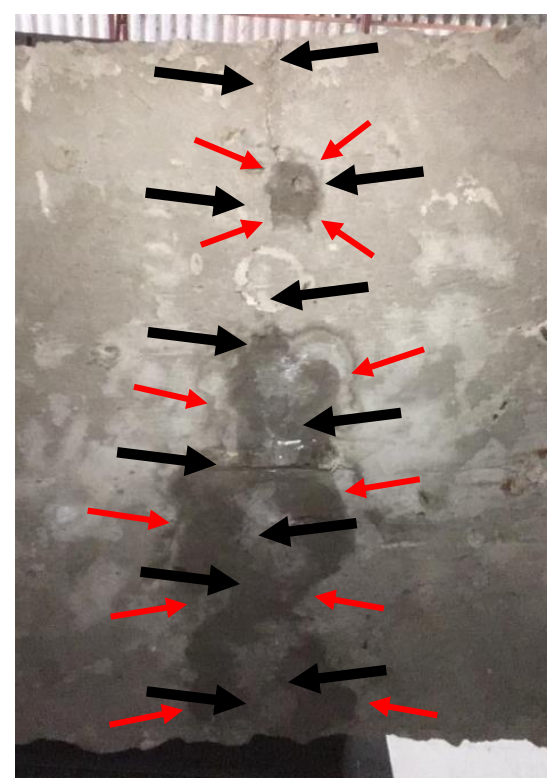

Figura 22: Dia 7 face inferior da laje com aditivo após fissuração.

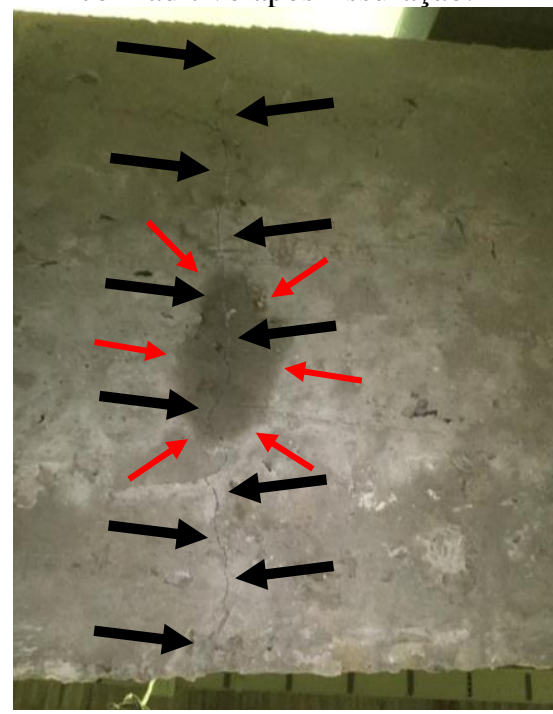

Figura 23: Dia 7 face inferior da placa referência após fissuração.

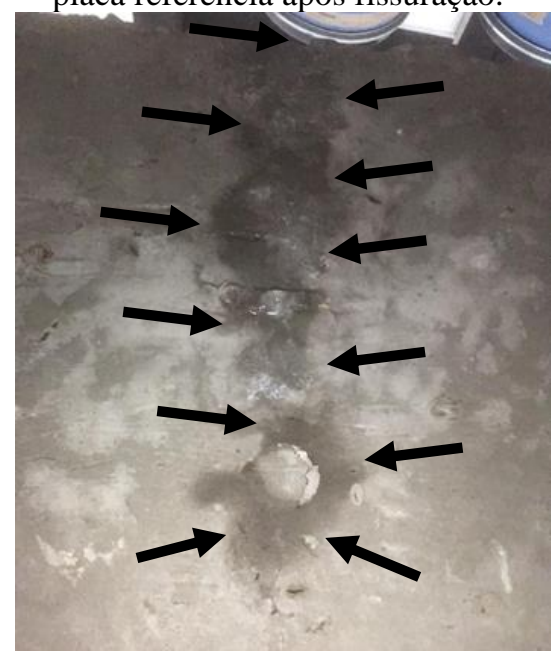

Figura 24: Dia 14 face inferior da placa com aditivo após fissuração.

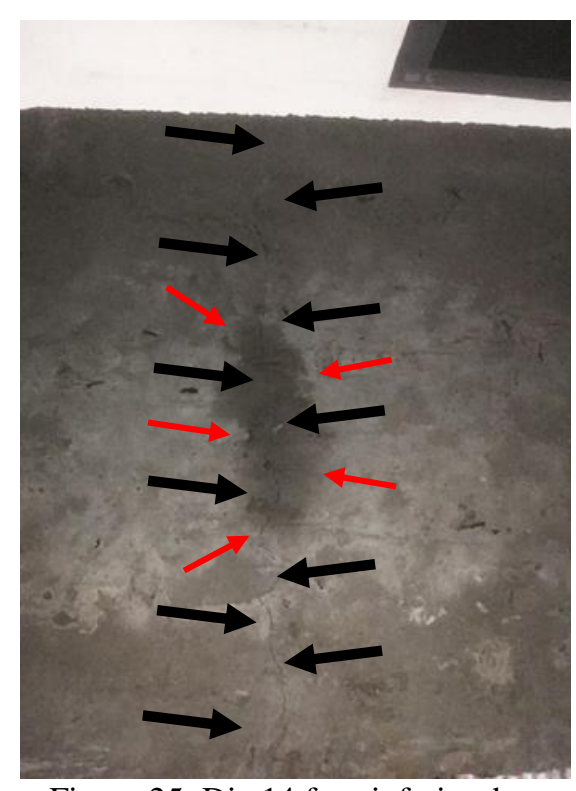

Figura 25: Dia 14 face inferior da placa referência após 2 fissuração.

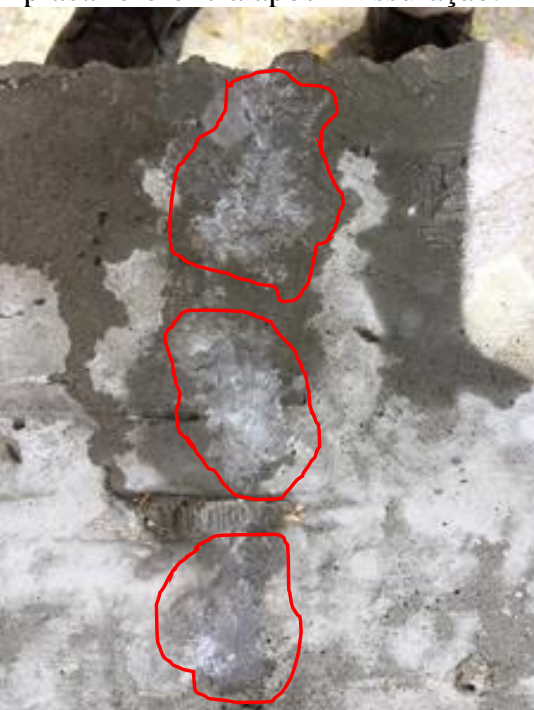

Figura 26: Detalhe do hidróxido de cálcio lixiviado na face inferior.

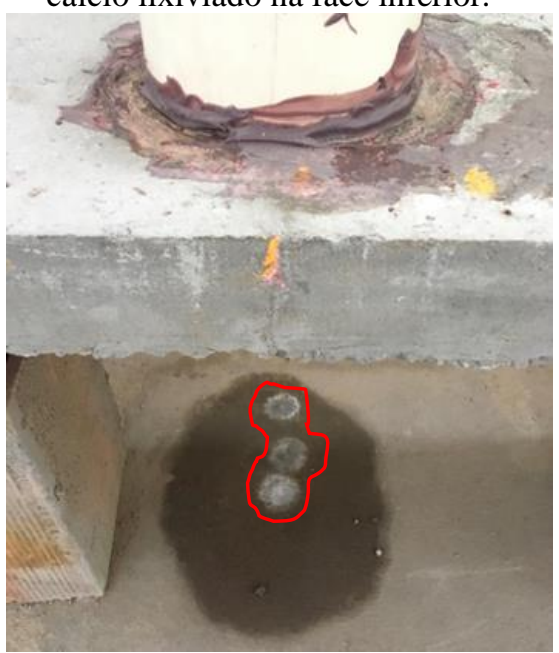

Figura 27: Detalhe do hidroxido de cálcio lixiviado sob a placa.

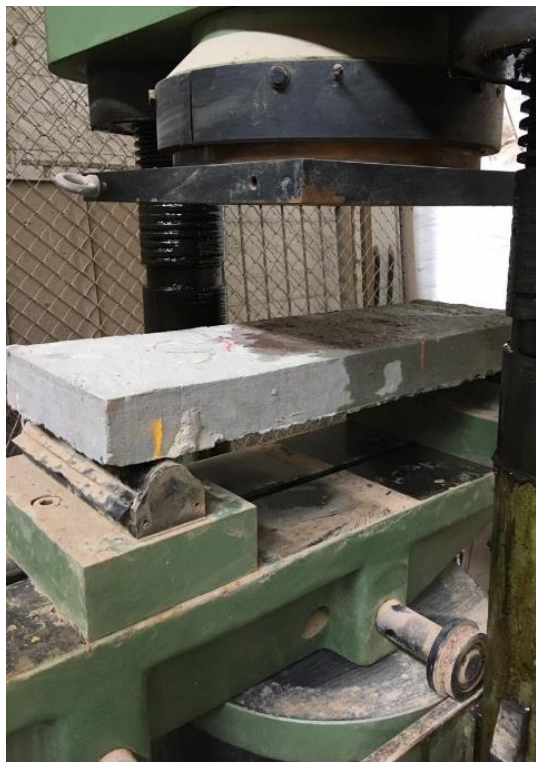

Figura 28:Ruptura total da placa para investigação de falha interna.

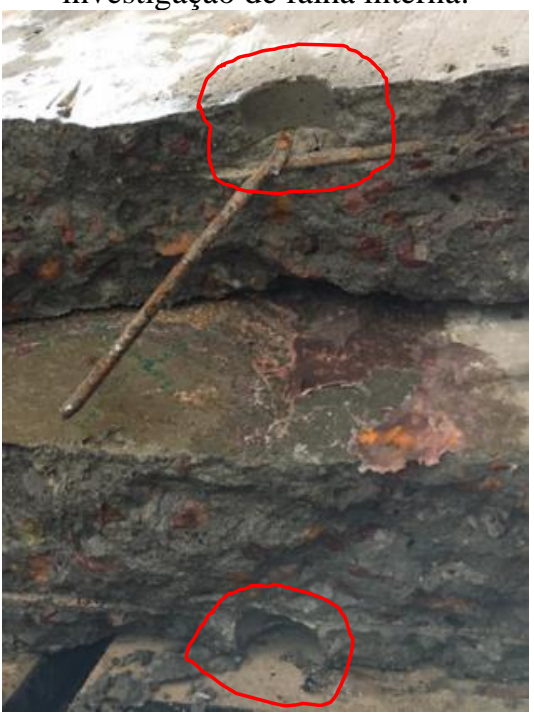

Figura 29: Falha interna da placa com aditivo critalizante.

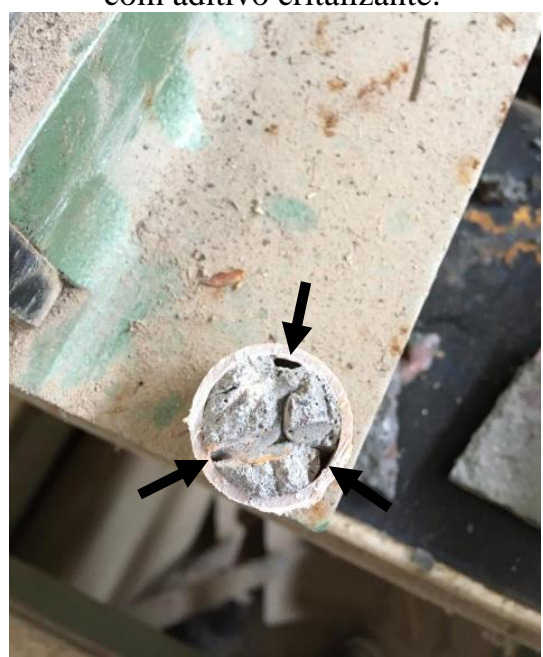

Figura 30: Detalhe mostrando vazios no concreto mal adensado. 


\section{CONSIDERAÇÕES FINAIS}

O método permitiu uma avaliação não normatizada a respeito da permeabilidade em concretos com adição de cristalizante e demonstrou os pontos a serem melhorados e desenvolvidos para novas avaliações. Percebeu-se ao longo do experimento que a laje de concreto com aditivo cristalizante apresentou claros sinais de autocicatrização. A lixiviação nesta placa foi ligeiramente precosse em comparação a laje sem aditivo cristalizante, o que demonstra indícios de funcionalidade do aditivo. Porém a diferença nos fluxos hidráulicos das duas placas foi muito grande, o que pode facilitar a formação de cristais na laje com aditivo cristalizante em comparação a sem aditivo cristalizante. A realização das placas com espaçadores improvisados ocasionou a formação de um nicho de concretagem na placa com aditivo cristalizante, dificultando avaliar as duas placas em igualdade de condições.

Muito se deve normatizar e melhorar para coletar-se dados precisos e análises reais sobre este tema, a funcionalidade dos aditivos cristalizantes na auto cicatrização do concreto. As lajes podem ter tamanhos menores, com espaçadores utilizados no mercado, com fissuras controladas de maneira que os fluxos hidráulicos sejam semelhantes, e maior tempo para avaliação comparativa entre as lajes. De uma maneira geral, notou-se que quando o concreto possui traço adequado como este desenvolvido mesmo quando aberta fissura de $0,4 \mathrm{~mm}$ a laje sem aditivo cristalizante somente umidificou sua face inferior, dando a entender que seus poros eram poucos permitindo pouca permeabilidade de água.

\section{REFERÊNCIAS}

ABNT NBR 5738: Concreto-Procedimento para moldagem e cura de corpos de prova. Rio de Janeiro, 2016.

ABNT NBR 5739: Concreto - Ensaios de compressão de corpos-de-prova cilíndricos. Rio de Janeiro, 2007.

ABNT NBR 8522: Concreto - Determinação dos módulos estáticos de elasticidade e de deformação e da curva tensão - deformação. Rio de Janeiro, 2003.

ABNT NBR 9575: Impermeabilização - Seleção e projeto. Rio de Janeiro, 2003.

ABNT NBR 9779: Argamassa e concreto endurecidos - Determinação da absorção de água por capilaridade. Rio de Janeiro, 1995.

ABNT NBR NM 67 - Concreto - Determinação da consistência pelo abatimento do tronco de cone. Rio de Janeiro, 1998.

BAUER, LUIZ ALFREDO FALCÃO. Materiais de Construção 1. - $5^{\text {a }}$ Ed. - LTC Livros Técnicos e Científicos - Rio de Janeiro, 1994.

HUSSEIN, J. S. M. Levantamento de patologias causadas por infiltrações devido à falha ou ausência de impermeabilização em construções residenciais na cidade de Campo Mourão - PR. 2013. 54 p. Trabalho de Conclusão de Curso (Graduação em Engenharia Civil), Universidade Tecnológica Federal do Paraná, Campo Mourão, 2013.

IBI Instituto Brasileiro de Impermeabilização. Disponível em: <http://www.ibibrasil.org.br/>. Acesso em: 20 mar. 2018.

MEHTA, P. KUMAS. Microestrutura, Propriedades e Materiais - 2a Ed. 2008 - IBRACON, 2008.

CUNHA, AIMAR; NEUMANN, WALTER. Manual de impermeabilização e isolamento térmico - $4^{a}$ Ed. 1979 - Rio de Janeiro - RJ.

PENETRON BRASIL LTDA. FOR006 - Ficha técnica de produto Penetron Admix - São Paulo, 2016 (FABRICANTE).

PETRUCCI, ELÁDiO G. R. Concreto de Cimento Portland - $6^{\text {a }}$ Ed. - atualizada e rev. por Vladmir Antônio Paulon Porto Alegre, 1978. 
PETRY, S. B. Estudo da permeabilidade à água na camada de cobrimento de protótipos de concretos com altos teores de cinza volante - RS. 2004. 111 p. Dissertação de mestrado, Universidade Federal de Santa Maria, Santa Maria, 2004.

PIRONDI, Z. Manual Prático de impermeabilização e de isolação térmica. São Paulo-SP: SBR Editora e Artes Gráficas Ltda., 1979. 140 p.

RECENA, F. A. P. Dosagem e controle da qualidade de concretos convencionais de cimento Portland. $3^{\mathrm{a}}$ Ed. EDIPUCRS, 2011 - Porto Alegre - RS.

ROMANO, C. A. Apostila de tecnologia do concreto. Paraná - PR: 102p.

SOUZA, Vicente Custódio Moreira; RIPPER, Thomaz. Patologia, Recuperação e Reforço de Estruturas de Concreto. São Paulo: Pini, 1998.

TAKAGI, EMILIO MINORU; ALMEIDA J, WALDOMIRO; OLIVEIRA FERNANDO SOUZA: artigo. Tratamento químico cristalizante para impermeabilização e proteção de estruturas de concreto armado: $46^{\circ} \mathrm{CONGRESSO}$ BRASILEIRO DE CONCRETO, 2004.

VERÇOZA, Enio José. Impermeabilização na Construção. Porto Alegre: Sagra 1987. 